\title{
When Crises Hit Home: How U.S. Higher Education Leaders Navigate Values During Uncertain Times
}

\author{
Brooke Fisher Liu ${ }^{1} \cdot$ Duli Shi ${ }^{1} \cdot$ JungKyu Rhys $\operatorname{Lim}^{1} \cdot$ Khairul Islam $^{2} \cdot$ America L. Edwards $^{3} \cdot$ Matthew Seeger $^{2}$
}

Received: 7 November 2020 / Accepted: 7 April 2021 / Published online: 12 May 2021

(c) The Author(s), under exclusive licence to Springer Nature B.V. 2021

\begin{abstract}
Against the backdrop of a global pandemic, this study investigates how U.S. higher education leaders have centered their crisis management on values and guiding ethical principles. We conducted 55 in-depth interviews with leaders from 30 U.S. higher education institutions, with most leaders participating in two interviews. We found that crisis plans created prior to the COVID-19 pandemic were inadequate due to the long duration and highly uncertain nature of the crisis. Instead, higher education leaders applied guiding principles on the fly to support their decision-making. If colleges and universities infuse shared values into their future crisis plans, they will not have to develop a moral compass on the fly for the next pandemic. This paper suggests the following somewhat universal shared values: (1) engage in accuracy, transparency, and accountability; (2) foster deliberative dialog; (3) prioritize safety; (4) support justice, fairness, and equity; and (5) engage in an ethic of care. To navigate ethics tensions, leaders need to possess crisis-relevant expertise or ensure that such expertise is present among crisis management team members. Standing up formal ethics committees composed of diverse stakeholders also is instrumental in navigating tensions inherent in crises. The next pandemic is already on the horizon according to experts. Through infusing values into future crisis plans, higher education leaders can be confident that their responses will be grounded in their communities' shared values.
\end{abstract}

Keywords Communication $\cdot$ Qualitative $\cdot$ Coronavirus $\cdot$ Disasters $\cdot$ Ethics $\cdot$ Leadership

As the coronavirus disease (COVID-19) spread around the world in spring 2020, thousands of U.S. universities were forced to migrate online, with little to no prior telework

Brooke Fisher Liu

bfliu@umd.edu

Duli Shi

shiduli@umd.edu

JungKyu Rhys Lim

rhyslim@umd.edu

Khairul Islam

kislam@wayne.edu

America L. Edwards

americaedwards@umail.ucsb.edu

Matthew Seeger

matthew.seeger@wayne.edu

1 University of Maryland, College Park, Maryland, USA

2 Wayne State University, Detroit, Michigan, USA

3 University of California Santa Barbara,

Santa Barbara, California, USA experience (Hess, 2020). Few, if any, higher education leaders were adequately prepared to respond to the COVID-19 pandemic. As The Chronicle of Higher Education (2020) noted when covering the pandemic, "The biggest issue that college and university officials face in 2020 may be one that few of them ever thought about before."

Crises, like the COVID-19 pandemic, are "high impact events that often strip an organization to its core values" (Seeger \& Ulmer, 2001, p. 374). Because crises are uncertain, chaotic events, they involve discretionary decisionmaking by organizational leaders (Boin \& Nieuwenburg, 2013). During crises, senior university administrators can serve as sources of guidance, strength, and resilience as their institutions' moral voices (Gigliotti, 2016; St. John III \& Pearson, 2016).

One reason why some higher education leaders may have struggled to respond to the COVID-19 pandemic and the related ethical tensions is that there is minimal guidance on how higher education institutions should respond to crises (CDC, 2020a; Gigliotti, 2016; Moerschell \& Novak, 2020). Likewise, how leaders should integrate ethical 
decision-making into their crisis management is a well-recognized research gap (e.g., Coldwell et al., 2012; Sellnow \& Seeger, 2020; St. John III \& Pearson, 2016), especially for public health crises like pandemics (Thomas \& Young, 2011; Thomas et al., 2007). To fill these knowledge gaps, we investigate how U.S. higher education leaders have centered their crisis management on values and guiding ethical principles in response to the COVID-19 pandemic. Specifically, we conducted 55 in-depth interviews with leaders from 30 U.S. higher education institutions, with most leaders participating in two interviews.

The central finding from our interviews is that to be prepared for future mega-crises like pandemics, higher education institutions need to explicitly integrate their community's shared values into future crisis plans and planning activities. Furthermore, higher education institutions need to co-construct these shared values with their key stakeholders, which include faculty, staff, students, and other community members. Standing up formal ethics committees is one way to institutionalize shared values into crisis responses. Leaders also need crisis-specific knowledge such as public health expertise. If they do not possess this knowledge, they need to ensure that crisis management team members can fill this gap.

The next section of the paper provides a synthesis of the literature that grounded our research questions. In each section, we thematically summarize the extant research, followed by our research questions. We then delve into our data collection and analysis approach, followed by the paper's results. In the final section of the paper, we cover the implications of the results for research and practice, along with the paper's limitations.

\section{Literature Review}

\section{Missions, Values, and Crisis Management}

The first research question examines how U.S. higher education institutions responded to the pandemic. In this literature review section, we synthesize research on how missions and values affect organizational crisis management.

Missions explain an organization's purpose, goals, behavior standards, and values (Campbell \& Yeung, 1991). A clear and meaningful mission can enhance mutual understanding among an organization's leaders and stakeholders, and support successful business operations (Cochran \& David, 1986). In a crisis context, missions can help organizations respond strategically, sustain employee morale, and communicate a shared sense of value among organizational leaders and stakeholders (Liu et al., 2012; Ulmer \& Sellnow, 2000). In sum, prior research has established the importance of missions in organizations' crisis responses, but has not delved deeply into how missions guide multiple organizations' responses to the same crisis, as we do in this examination of the COVID-19 pandemic. We now turn to a discussion of how organizational values connect with crisis management.

Organizational values are a significant part of organizations' missions; values are "the beliefs and moral principles that lie behind the company's culture" (Campbell \& Yeung, 1991, p. 15). Through values, organizations establish norms and behavior standards (Campbell \& Yeung, 1991). Organizational values are "both enduring and capable of change" (Bourne \& Jenkins, 2013, p. 498). We propose that crises are moments when values may evolve. Prior research finds that strong organizational values support organizations' ethical decision-making (Pearson et al., 1997; Prewitt \& Weil, 2014). Overall, there is a shared understanding of the importance of strong organizational missions and values in responding to crises, but little empirical research on this topic. Thus, the following research question is addressed.

RQ1: What are the roles of (a) missions and (b) values in U.S. higher education institutions' responses to the COVID-19 pandemic?

In addition to strong organizational missions and values, adherence to appropriate ethical frameworks, guidance, and codes can help organizations manage crises. Indeed, developing plans that address ethical challenges and conducting training are essential to help organizations navigate sticky situations inherent in crises, as we further discuss below.

\section{Ethics, Crisis Planning, and Crisis Responses}

Crisis, as we noted, is a context fraught with ethical questions and tensions. These may involve accusations of wrongdoing, treatment of those harmed, issues of equity and fairness, questions about honesty and transparency, as well as tensions over financial costs (Sellnow \& Seeger, 2020). Training can foster organizational reflection about ethical challenges and establish the crisis management team's commitment to ethical responses (Wynia, 2007). An essential part of preparation is developing a crisis management plan (Coombs, 2019). Yet, research reveals that few crisis plans adequately address how to navigate ethical dilemmas inherent in public health crises (Braum et al., 2009; Thomas \& Young, 2011; Thomas et al., 2007). Furthermore, ethics are typically only considered in plans after transgressions occur, rather than being integrated proactively into routine preparation activities (Thomas \& Young, 2011). Instead, plans and other preparedness activities should include clear and welldocumented answers to common ethical questions and issues along with scenarios to best prepare leaders for public health emergencies (Leider et al., 2017; Phillips et al., 2009). While inadequate attention has been given to ethics and its role in crisis decision-making (Sellnow \& Seeger, 2020), there is 
a growing body of scholarship on principles to guide crisis decision-making. We synthesize that scholarship below.

\section{Guiding Principles}

Be Virtuous A guiding ethical principle for university administrators is committing to the highest level of integrity (The American Association of University Administrators, 2017). Integrity is generally framed in terms of virtue ethics (St. John III \& Pearson, 2016). Virtuous crisis responses include considering the immediacy of the response and providing support to those impacted through an ethic of care (Louden, 1992; Seeger \& Ulmer, 2001; Sellnow \& Seeger, 2020). Virtuous leaders exhibit a strong sense of social responsibility, accountability, and justice (Leider et al., 2017; Sellnow \& Seeger, 2020). These leaders do so by consistently prioritizing stakeholder well-being over legal obligations (Phillips et al., 2009; Seeger \& Ulmer, 2001; Streifel et al., 2006). Through embracing an ethic of care, virtuous leaders prioritize building and sustaining "morally sound relationships" with stakeholders (Maak \& Pless, 2006, p. 5; Pullen \& Vachhani, 2020). Virtuous leaders use a welldeveloped sense of responsibility to center on purpose, principles, people, power, and relational intelligence (Coldwell et al., 2012; Maak \& Pless, 2006; Varma, 2020).

Consider the Consequences Organizational members should reflect on the consequences of their communicative behaviors for their stakeholders and society (Heath, 2006; Huang, 2004). This includes careful consideration of the benefits and burdens associated with response decisions and distributing these benefits and burdens fairly (Braum et al., 2009; Phillips et al., 2009). Two ethical theories guide considering the consequences: utilitarianism and justice. Utilitarianism broadly considers the greatest good for the greatest number, while justice considers fairness for all stakeholders (St. John III \& Pearson, 2016). In public health emergencies, there is an inherent tension between protecting the health and safety of communities (i.e., utilitarianism) while considering the liberties and unique needs of individuals residing in those communities (i.e., justice) (Braum et al., 2009).

To navigate the impacts of crises, managers should consider fair access to information, treatment, resources, fair reimbursement procedures for patients, and reasonable liability protections for those responding to public health crises (Braum et al., 2009; Hodge et al., 2013). Consideration should assess whether or not implementing a response measure would cause greater harm, and if there are less restrictive options that could accomplish the same public health objectives (Braum et al., 2009; Hodge et al., 2013). Similarly, a guiding ethical principle for university administrators is upholding the values of fairness and equity, while serving all members of campus communities (American Association of University Administrators, 2017).

Be Transparent According to the principle of significant choice, organizations should communicate as completely and as accurately as possible to help community members make important decisions (Sellnow \& Seeger, 2020; Streifel et al., 2006). In doing so, leaders should be cautious of claims of urgency and, instead, should make legitimate claims that are transparent (Leider et al., 2017; Rawlins, 2009; Spector, 2019).

Determinants of transparency include timeliness, relevance, accuracy, reliability, and clarity (Rawlins, 2009). Organizational transparency is "the reputation an organization holds for transparency;" this reputation emerges from media coverage, recommendations from others, and stakeholders' prior interactions with the organization (Auger, 2014, p. 339). A guiding ethical principle for university administrators is striving for accuracy and transparency (American Association of University Administrators, 2017).

Engage in Deliberative Dialog Prior research emphasized the importance of deliberative dialog with key stakeholders (Braum et al., 2009; Huang, 2004). Engaging in deliberative dialog enables leaders to understand stakeholders' diverse and sometimes competing crisis interpretations along with the underlying issues that spark crises (Braum et al., 2009; Spector, 2019). Conducting deliberative dialog is especially important for understanding stakeholders' "culturally influenced expectations" (St. John III \& Pearson, 2016, p. 28; Littlefield et al., 2009). Deliberative dialog also has a role in crisis preparedness. Ethical deliberation through rulebased exercises may help crisis management teams prepare to make ethical decisions (Boin \& Nieuwenburg, 2013), including how to seek support in making ethical decisions (American Association of University Administrators, 2017). Whether deliberative dialog occurs during the planning or response phases, the goal is to engage in discussions to improve ethical decision-making during crises rather than to obtain consensus (Boin \& Nieuwenburg, 2013).

\section{Codes of Ethics}

Codes of ethics are one way to institutionalize guiding principles so that ethics guide decision-making during crises (American Public Health Association, 2019; Erwin, 2011; Thomas \& Dasgupta, 2020). Codes articulate an organization's norms and values and can be instrumental in guiding ethical crisis responses (Stevens \& Buechler, 2013). In public health emergencies, codes are important for supporting consistent decision-making given that any decision can have profound impacts on the community and individual outcomes (Hodge et al., 2013). Simply having a code, however, 
does not guarantee an ethical crisis response (Stevens \& Buechler, 2013). To be effective, codes should be transformational (i.e., focus on organizational change), instructional (i.e., provide actionable information), and relational (i.e., facilitate trust in an organization and its leaders) (Erwin, 2011; Stevens \& Buechler, 2013).

In addition to the organizational codes of ethics, professional codes of ethics guide the goals and beliefs of a group of professionals, and frequently require "higher standards than are legally mandated" (Stevens, 1994, p. 64). Shortly before the emergence of COVID-19 in China, the American Public Health Association (2019) published a revised code of ethics. The code established the following core values: (1) professionalism and trust, (2) health and safety, (3) health justice and equity, (4) interdependence and solidarity, (5) human rights and civil liberties, and (6) inclusivity and engagement. Given the minimal prior research on how higher education institutions should prepare for and respond to crises, especially in public health contexts (Gigliotti, 2016; Moerschell \& Novak, 2020), we ask:

RQ2: What guiding principles, if any, have U.S. higher education institutions employed to ethically respond to the COVID-19 pandemic?

RQ3: To what extent have codes of ethics guided U.S. higher education institutions' responses to the COVID19 pandemic?

RQ4: How have U.S. higher education institutions responded to ethical tensions during the COVID-19 pandemic?

\section{Method}

To explore our research questions, we conducted in-depth interviews with 37 leaders from 30 U.S. higher education institutions between May and October 2020. In total, we conducted 55 interviews.

\section{Participants}

We used a combination of snowball sampling and maximum variation to secure interviews with a diverse group of higher education leaders. First, a list of participants was developed through personal connections. Given that it is difficult to access leaders during crises (Ha \& Riffe, 2015), the researchers used their personal experience in higher education administration to gain access to the first round of interviews.

The team then supplemented their networks by purposefully seeking leaders at institutions that were not well represented in the first round of interviews. Specifically, the research team used the Carnegie Classifications of
Institutions of Higher Education (The Carnegie Classification of Institutions of Higher Education, 2020) and emailed leaders at the institution types not well represented in the original sample to request an interview. In total, the team reached out to leaders at 137 institutions to secure 29 interview participants. The team ended recruitment when ongoing data analysis indicated theoretical saturation (Corbin \& Strauss, 2015). All leaders provided written consent to participate.

To be included in our sample, participants had to be involved in their institutions' crisis response to COVID-19. Participants served in roles such as chancellors, presidents, vice presidents, provosts, deans, and professors at a range of institution types, as classified by the Carnegie Classifications of Institutions of Higher Education (2020). We recruited a variety of participants from each category to ensure we had a representative sample, knowing there are differences in enrollment size, research funding, graduate program access, and so on.

\section{Interviews}

Prior to conducting interviews, participants completed a brief survey, which helped structure the interview questions. The survey was conducted via qualtrics.com and included 22 questions. Most notably, $84 \%$ of participants $(n=21)$ were employed at institutions that had pre-existing crisis management plans and $71 \%$ of those participants $(n=15)$ answered that their plans included infectious disease outbreaks. Four participants (19\%) did not know if the plans included infectious disease outbreaks, while only two participants said their plans did not mention such outbreaks.

After participants completed the survey, we conducted initial semi-structured interviews with 37 participants from 30 institutions. These initial interviews lasted from 20 to $61 \mathrm{~min}$, with an average of $46 \mathrm{~min}$. The same question guide was used across all interviews. We also tailored interview questions based on participants' survey responses (e.g., asking how an institution used preparedness plans when a respondent indicated that they had such plans in the preinterview survey). Example questions from the interview guide include: "What have been your guiding principles or values in your continued response to COVID-19?" and "Are there particular tensions or points of conflict that have emerged as your school or college has responded to COVD19? If so, what are those"?

Each interview was conducted and recorded via Zoom and then professionally transcribed. Three to 10 weeks later, we conducted follow-up interviews with leaders from 25 of the 30 original institutions. These interviews averaged $24 \mathrm{~min}$ in length, with a range of 14-39 min. One participant 
had retired, one participant declined to participate, and three participants declined to respond to follow-up requests.

\section{Analysis}

The object of analysis for this research is U.S. higher education institutions' crisis responses to the COVID-19 pandemic. This approach reflects the literature on crisis management, and the view that communication processes cannot be separated from the crisis response (Coombs, 2019; Sellnow $\&$ Seeger, 2020).

With these assumptions in mind, the research team used the qualitative analysis software provided by their institutions (NVivo and Atlis.ti) to inductively and deductively code transcripts (Lindlof \& Taylor, 2011). To deductively code, the team created an initial list of codes from the literature review, which included codes such as mission, vision, code of ethics, tensions, crisis plan, and guiding principles. The guiding principles code included the following subcodes: be virtuous, consider the consequences, be transparent, and engage in deliberative dialog.

Next, team members engaged in a first round of coding to apply the deductive codes from the literature review, and then met to discuss codes that emerged inductively. At that stage, we added the following codes: teaching-focused institution, research-focused institution, organization type (i.e., religiously affiliated institution, public vs. private, and research-focused institution), organizational size, shared governance, and follow a track of value. We also added subcodes to some of our initial deductive codes. For example, for the guiding values code, we added the following subcodes: prioritize safety and support justice, fairness, and equity.

After revising our codes, the team divided into small groups. Two team members coded for each research question. We employed Corbin and Strauss's (2015) grounded theory analytics strategies, which include (a) constantly questioning the data through re-analysis and developing provisional answers to the research questions; (b) making comparisons among participants' insights and the prior literature; (c) employing researchers' life experiences to understand the data; (d) looking carefully at participants' language choices; (e) looking for outliers and negative cases; (f) using participants' own words to label codes when possible; and (g) reflecting on the biases and assumptions that researchers may bring to the analysis and pushing back on those "red flags" (p. 98). The next section presents the findings that emerged from the team's analysis. In reporting the findings, we used pseudonyms to protect the interview participants' identities.

\section{Findings}

\section{Missions and Values (RQ1a and RQ1b)}

The first research question asks about the roles of U.S. higher education institutions' missions and values in their responses to the COVID-19 pandemic. The results showed several prominent themes, as summarized below.

\section{Organizational Identity}

Half of the participants mentioned how their institutions' identities drive how they have responded to the pandemic. In other words, the question of "who they are," as reflected in their missions, determines their COVID-19 responses. For some participants, identity comes from their institutions' religious affiliation. For example, Drew shared:

We are a Vincentian university. So, we consider ourselves as mission-driven. We're not here to make money. We're not here to make great discoveries or do research. We're here to teach students. I think it's actually the Catholic tradition, which is centered on how do you make people's lives better? That's the entire reason that our university exists.

For others, their organizational identities come from whether their institutions are public or private. Riley commented: "We're a public institution and that means we have to serve the public good." Riley further noted that serving the public good including adapting in the face of the pandemic. Riley shared:

And we have a brand new medical school. This year we graduated our very first class of doctors who graduated two months early so that they could do their final clinical work in hospitals working on COVID-19.

As Dakota explained, this private (versus public) organizational identity could determine an institution's overall values:

I think a little bit about my experience being at private institutions versus a public institution is what you consider your values and what you consider your ethical framework in private institutions.

Institutional identity also comes from organizational size. Leaders of small institutions emphasized that their organizations prioritize making personal connections with students, which is challenging during a pandemic. As Gracen summarized:

We are a community that wants to connect people. You have a hard time connecting people from a social distance perspective...And so we're trying to figure out 
how do you package this unique, personal experience within the complement of safety and health?

Another important part of organizational identity are the specific populations that institutions serve, which include populations of color, international students, veteran populations, first-generation college students, and students with special needs (e.g., students with hearing loss). As Nolan mentioned: "And so our response has to be considered within that cultural and linguistic frame [of the population that we serve]." Similarly, Blake shared: "Veterans for us is an area of specific need because their scholarships and their requirements are different from a general scholarship student."

Leaders at institutions with strong research missions prioritized bringing research operations back for their graduate students and faculty. Owen reflected:

I hadn't thought about it until it was happening, a lot of these are grant-funded research projects and they have an end date...The worry was that if they keep paying students on these grants, the money is going to run out and the work isn't done based upon the expectations of what they were awarded.

Like many leaders, Avery noted the importance of bringing back research operations, as well as the relative ease of doing so: "Bringing back research is probably the safest and easiest thing to do. Most [faculty] are used to working in environments where it's just them and they often follow rules, and they don't want people to take them away from their research."

\section{Main Missions}

Participants mentioned two main missions: the academic mission that existed pre-pandemic and the health and safety mission that has dominated COVID-19 responses. Speaking to the importance of prioritizing the academic mission, Nolan commented:

A commitment to students and their education, all throughout the spring semester and in our planning in summer and our planning for fall. A commitment to providing the highest quality remote education is a key message.

Many participants discussed these twin academic and health/safety missions as intertwining. For example, Parker mentioned:

So trying to do both, provide them with the product that they're paying for at the same time as providing them with the safety that they deserve and that we're committed to doing.
Leaders further noted that the COVID-19 pandemic has challenged prioritizing their educational missions with foregrounding the health and safety of their campus communities. Hunter explained:

The mission to educate students is something that almost feels like it's not exactly on par with health and safety sometimes. For instance, if there is a snow emergency we sort of do all we can to stay open...I think that it was quickly realized that this [COVID-19] was a major health and safety issue.

\section{Planning, Codes of Ethics, and Guiding Principles (RQ2 \& RQ3)}

The second research question asks what guiding principles U.S. higher education institutions have employed to ethically respond to the COVID-19 pandemic. The third research question asks to what extent codes of ethics have guided U.S. higher education institutions' responses to the pandemic. Below we summarize the findings in response to these questions.

\section{Inadequate Relevant Prior Planning}

As noted in the method section, $84 \%$ of our participants are leaders at institutions that had crisis management plans. Yet, our leaders agreed that these plans were not as helpful as they could be for COVID-19. Morgan most succinctly characterized the situation as follows: "We're building the plane while it's in the air." Only a few participants indicated that they used their crisis plans to respond to COVID-19, typically only in the early stages of their response. For example, Hayden recalled:

We would go back and use it [the plan] kind of as a checklist because things were moving really fast for a few weeks in March, but we were able to circle back to the plan and make sure that we hadn't left anything out.

Most participants, however, indicated that their plans were inadequate due to the pandemic's unique and massive impacts on operations, the long duration of the crisis, and the unpredictable nature of the pandemic. Speaking about their institution's inadequate planning, Blake explained: "We had planned for a crisis that didn't really take place with as much disruption." Like other participants, Parker noted the unique nature of the COVID-19 pandemic. Parker shared: "We do have plans to evacuate the campus, but this wasn't an evacuation situation. So, very novel for us." Many participants commented on the unpredictable nature of the pandemic, which made prior plans inadequate. As Jo explained: 
We had crisis management plans. There was a pandemic plan. Were they adequate? No. And was it possible to address this type of thing in a totally proactive way? No, I don't think anybody would've guessed that this would go the way it went.

Furthermore, according to the participants, none of their institutions' plans included codes of ethics or other formal ethics components. Therefore, it is perhaps unsurprising that none of the participants discussed formal codes of ethics that guided their COVID-19 responses. Instead, leaders advocated for following a track of value through guiding principles, as further discussed below.

\section{Follow a Track of Value}

Rather than following an established crisis plan, several participants advocated for developing guiding values for their COVID-19 responses. In some cases, this was because no plan existed or existing plans did not adequately address a pandemic. As Blake shared, "We followed a track of value rather than a crisis plan. We didn't have a plan." As another example, Sam observed, "We've really had to go back to the drawing board and say, 'What does the ethical framework look like for crisis management?"

While developing a track of value ideally happens in the crisis planning phase, leaders noted that these values can also be developed during a crisis. Nolan recalled, "We set up a series of guiding principles to guide how we wanted this work to happen and while the financial aspect was obviously important, the guiding principles really reminded us what was most important." Similarly, Bailey shared that their institution's president set up two important committees to guide their response. The first committee was a group of on-campus public health and medical experts. The second was an ethics and privacy committee. Bailey elaborated by noting:

And that second committee was asked to consider some of the ethical and privacy issues associated with coping with a pandemic, planning for a fall semester and what were the features that this ethics group felt were important to keep in mind and to really make sure we were attentive to, as we were making our plans.

Although only a few participants discussed forming ethics committees or developing formal value statements to guide their institutions' COVID-19 responses, all participants shared how values guided their responses, as synthesized below.

\section{Guiding Values}

Engage in Accuracy, Transparency, and Accountability Almost all of the participants prioritized the intersection of accuracy and transparency. A few participants further linked accuracy and transparency to accountability. Parker summarized this intersection as follows:

Transparency continues to be a base principle with a few caveats in that I'm making sure that what we present is accurate and easy to understand and not so easy to misinterpret. So that part's been tough...And it's not about not being willing to share it. It's not being willing to share information that we can't effectively educate them on. Positivity rate is an example of that. We can say we had 6 out of 10 cases positive, so somebody could conclude that $60 \%$ positivity rate. It's like, 'No, that was a small scale population.' Anyway, there's a lot of nuances that are complicated.

Multiple participants discussed the challenge of being accurate and transparent while dealing with a rapidly evolving situation. As Alex observed:

We're guessing just like everybody else. We're certainly using data and research and saying this is our best estimate of where we need to be. But people are looking for guarantees...I can make a best guess, but I can't guarantee.

To balance the need for accuracy, transparency, and a reasonably swift crisis response, Emerson recommended an " $80 \%$ solution" rule: "Get people to accept that they can't have all the answers. So I always say when you get to an $80 \%$ solution, it's time to move. That's it. You don't have time for more." Nolan recommended delaying decisions whenever safe to do so: "If you have the capacity, if something is working at the moment, there are many times when it doesn't pay to make that instantaneous change as long as you're comfortable with where you are." Like other leaders, Gale advised not over-promising: "I tried to be very careful to not say too much or to not make promises. Don't say we're going to have access to 10,000 masks if we don't know if that is possible." Several participants noted one advantage that research universities have. As Casey explained, these institutions can "quickly pull in faculty specialists" in areas like risk communication and public health to support accurate and transparent responses.

Leaders described factors that contribute to building a campus culture of trust in leadership, including building strong pre-crisis relationships and having leaders with crisisspecific knowledge. Hunter summarized these two factors as follows: 
It's built on trust, and it's trust that was developed previously and that gets reinforced through as much transparency and communication...It helps to have a provost who's a physician and an economist...And I think that that buys us a lot of credibility because he understands the science and the public health issues, but he also understands the importance of maintaining our academic enterprise.

A common thread among participants was the added credibility that campus leaders brought to the table when their expertise included public health or medicine.

Foster Deliberative Dialog All of the participants discussed the importance of engaging in deliberative dialog with their primary stakeholders: students, faculty, and staff. Deliberative dialog most frequently occurs through virtual town hall meetings, but also through asynchronous vehicles including stakeholder surveys, anonymous forms to report concerns, and establishing dedicated email addresses for COVID-19 concerns. Lee characterized the importance of deliberative dialog as follows, a sentiment shared by most participants:

We've done just an incredible amount of virtual town halls, where we're literally just taking questions from people, and those have been targeted to different audiences. Some have been for all on campus, some have been just for instructors, some of them for parents, some of them for students, some have been for student affairs staff.

Dakota explained why having town halls and other opportunities for feedback is critical: "Ultimately, I think what it's helped us is to realize that involving more people and being more open helps identify where there are issues that you might not have thought of yourself, as well as where miscommunication might happen."

In some cases, engaging in deliberative dialog focused on listening and expressing compassion for stakeholders. In other cases, participants explained how deliberative dialog had a direct impact on their pandemic response, including safety protocols, message strategies, and leadership presence on campus. A few leaders discussed how engaging in deliberative dialog allowed them to connect with groups that have been historically marginalized on their campuses. As Taylor commented:

Getting people to realize that of all the ways we could be spending part of our time, even in the midst of this crisis, actively engaging each other and try to move past the structures that have impeded the progress of various groups in our society is incredibly important.

While the vast majority of participants discussed planned deliberative dialog, a few participants showcased the role of spontaneous deliberative dialog in their crisis responses. For example, Sam noted:

I try to be omnipresent...I'll stop in before a class begins and ask them how it's going, have you had any problems, can we support you in any way differently? So, just being very active and very inclusive and focused on people and human relationships, which I found in my own career really matters.

Furthermore, almost all participants emphasized the critical benefits of deliberation with their peers in leadership positions. Peer consultation includes formal groups, like peer members of associations and peer leaders at institutions within the same state or university system. For example, Bailey noted:

The other group that we did, I think have a lot more interaction with and this is largely the presidents interacting, was the Association of American Universities... It was basically an opportunity for presidents to share in a confidential setting what the concerns were, what the challenges were going to be, and what the opportunities look like for the fall.

However, some participants noted a few drawbacks to dialog with peers. Avery shared that sometimes there were too many peer-to-peer dialog requests and that it was important to focus on the "day job that's really busy." Kelly noted the role of "prestigious institutions" and observed that these institutions "led the way and I think everybody else followed." Despite all the dialog that participants engaged in, multiple participants expressed frustration that deliberative dialog does not always lead to the desired outcomes, especially student compliance with safety guidance.

Prioritize Safety All participants discussed the imperative of prioritizing their stakeholders' safety, especially the safety of students, faculty, and staff. As Morgan noted:

I think number one is safety. That's the thing that stands out. I told my own leadership team that this is not a time for popularity. We have to throw popularity out the window and do what's right. That's based upon data-driven decisions and people being safe.

Participants shared a variety of measures to prioritize safety. Some of these measures involve compliance initiatives such as required COVID-19 tests, safety pledges, and safety videos. Institutions also have trained students to serve as peer enforcers, launched social media compliance campaigns, and enacted consequences for those who violate established expectations. For example, discussing one popular approach to promoting on-campus safety and compliance, Owen shared: 
We're doing a contest where on social media, you could give in either artwork, a poem, a video, some way that you are protecting your health and the health of others. And then every two weeks we're going to pick a winner and then they get AirPods or a lawn chair as a surprise.

Other measures include canceling spring break, suspending study abroad opportunities, moving some or all classes online, limiting dorm density, limiting dining services, lowering staff presence on campus, and moving events online. While most participants discussed social distancing measures their institutions have taken along with purchasing personal protective equipment as positive steps, a few participants emphasized the importance of making science-based decisions. For example, Drew said:

We're not going to do things just to be, as we call it, 'TSA [Transportation Security Agency] theater.' When you think about going to the airport. We're only going to do things that are backed up by science and are effective. We're not going to do it just because it looks good.

For many leaders, prioritizing safety needs to be balanced with the fiscal realities of the pandemic. A few participants further shared that their institutions' fiscal limitations directly impact their capacity to enact safety measures. As Sam explained:

I think one of the things that really separates the haves and the have nots is the decision whether they're going to test students and whether they're going to test employees and do scanning. For those institutions that have a hospital or a hospital system, it's much easier for them to do that.

Furthermore, several participants conveyed that while some federal and state guidance certainly helped them decide how to respond safely to the pandemic, they also had to make judgment calls. As Ezra noted,

Recently the governor issued another executive order allowing indoor eating to a certain capacity, but we're not allowing indoor eating in our dining facilities. We're continuing to allow only grab and go. So, that is an example of how we're working closely with our state government, but at the same time, we're making decisions that we feel will help keep our community even safer.

Making judgment calls was especially important given how rapidly some government guidance changed, as noted by our participants.
Support Justice, Fairness, and Equity Almost half of our participants emphasized the importance of considering justice, fairness, and equity in their COVID-19 responses. In discussing this guiding principle, participants focused on their at-risk stakeholders including community members with health conditions that put them at higher risk for contracting COVID-19, members of marginalized communities, and members of communities especially hard hit by COVID-19. As Nolan explained:

We made a number of decisions in spring that were hard for some of our community except in the name of equity. We only get pass/fail grades. We didn't allow anybody to take a letter grade for spring just for that semester and students couldn't quite understand that. And again, and again, and again, some students, we would explain the inequities that some of our students experienced that meant it wasn't reasonable to offer the grades.

In the same spirit of equal access, Quinn explained: "We developed a working group on inclusion and equity to look at how COVID-19 is disproportionately impacting some of our community members who are people of color." Many participants discussed providing loaner laptops and hotspots for students who did not have reliable Internet access at home. To further support disadvantaged students, participants discussed allowing some students to stay in the dorms if they did not have a safe home to go to or traveling home was not an option, as was the case for many international students. One participant mentioned food insecurity and the importance of keeping campus pantries well stocked even when the majority of students are not on campus.

In discussing student populations with specific needs, participants often mentioned undocumented immigrants and international students. Participants also discussed the power hierarchies inherent in academic institutions, which means that some community members have less social capital to push back on how institutions handle the pandemic. As Shannon explained: "Faculty seem to have a little more flexibility and tenure is a wonderful thing... But a staff member can't do that...Some staff are feeling this kind of social class issue." Several participants noted that sometimes institutions have no choice but to bring back staff who are essential workers like dining services and custodial staff. Riley elaborated on this challenge as follows:

We make sure we are screening out people with preexisting conditions, or maybe who live in multi-generational families. We make sure that we provide them with PPE [personal protective equipment] and social distancing and all of that. But you still can't get around it, that we're asking them to put their lives a little bit 
more at risk than other people in our community. And I think that's a moral dilemma.

\section{Engage in an Ethic of Care}

As previously noted, participants unanimously agreed that their highest ethical responsibility was to protect the health and safety of their community, reflecting a strong ethic of care. In addition to focusing on campus safety, participants discussed other approaches to fostering a positive climate through an ethic of care. Several participants discussed creating social media videos to connect with students not on campus. As Jamie shared: "We have a woman who works in our dining hall named Miss [name removed]. She always hugs all the students who go in to dine, and so we have a video of her saying how much she misses them."

Other participants emphasized the importance of sustaining community through creative, mostly virtual events. Examples include trivia nights, paint-by-number classes, a sign-up for a character artist, and pop-up events like socially-distanced movie night in football stadiums. Gracen summarized the motivating factor behind these events for their campus as follows: "We don't have all the answers... So what can I do to make your day better today?"

A few participants discussed an overall philosophy of care for their campus stakeholders. For example, Sidney noted: "I care deeply about staff. I care deeply about our students." Similarly, Ezra explained: "We have moved mountains. We have done every possible thing that we could to support students. For me, that's that hallmark of who we are as a small campus, it's a very personal relationship that we have with students."

A personal touch in their COVID-19 response was mentioned by several participants, especially those at small institutions and/or private institutions. This approach included handwritten cards from university leaders to students, faculty, and staff along with small appreciation gifts like free pizza or fruit baskets. Some participants mentioned new programs that institutionalized a personal touch during the pandemic. For example, Lee shared:

We have a program that's called [mascot name removed] Care. And the program is faculty and staff who volunteer to reach out to students. They text them, they email them, they call them, and they made sure that those students were doing okay.

Other participants discussed programs that expressed an ethic of care through directly meeting faculty and staff needs related to the pandemic. Examples included offering training on how to teach online, how to support community members experiencing mental distress, and how to conduct performance evaluations during the pandemic. Additionally, Bailey mentioned a "COVID bank" in which 3,000 employees voluntarily took furloughs to help the institution reduce costs while supporting the needs of vulnerable campus community members. Some participants discussed tenure clock extensions.

\section{Ethical Tensions (RQ4)}

The fourth research question asks how U.S. higher education institutions have responded to ethical tensions during the COVID-19 pandemic. Participants identified four tensions they have faced while responding to the pandemic, as further discussed below.

\section{Mission vs. Financial Solvency}

First, several participants discussed a tension between meeting their institutions' educational missions while staying financially afloat. As Hayden explained:

I never wanted to be in the position where we were making a decision because it was the best thing to do financially. I wanted to make sure that it was still a good thing to do with people's health and safety as well. So we have had to balance that being a state institution, we don't have a lot of the funding strings that some of the public schools have available to them or the increased tuition.

Several participants discussed how U.S. higher education institutions have built a business model that relies on revenue auxiliary services (e.g., dining, housing, recreational services, athletics), but during the pandemic revenue from those services has been eliminated or severely diminished. As Jordan noted: "If students are not on campus, then those services go unfunded, and yet they still have to be paid for."

\section{Competing Stakeholders' Desires}

Second, leaders frequently discussed the competing desires, and sometimes demands, of their stakeholders. Tensions have emerged between students' preference for in-person courses and faculty preference for virtual classes. As Finely noted:

It's been a balancing act because we have our students and parents and families, they want to be back on campus. They want to have their college experience. And our faculty, being of an older age group, wanted the option to either teach on-line or in-person and they were able, they pushed for that and they got what they wanted on that. So, I would say that finding a com- 
mon ground between both of those groups is part of the game.

As previously noted, tensions also exist among staff and faculty, in part due to academic hierarchy. As Riley explained, leaders can successfully navigate those challenges by offering compromises, such as researchers cleaning their labs rather than custodial staff.

\section{Compliance Challenges}

The third tension that participants discussed related to compliance challenges, especially when it comes to social distancing and properly wearing masks. Dakota summarized this challenge as follows:

So it's challenging because we have compliance, but we also have people who are not complying. So at what point, what do we do about that? Do we remind people? Do we discipline people? Do we implement stricter rules for the whole campus? Do we say, 'We don't have enough compliance, and so everybody has to go home and we're back to working remotely again or learning remotely?'

Multiple participants discussed an approach that begins softly and then becomes more severe if noncompliance continues. As Parker explained:

We liken it to our no smoking policies on campus when it comes to things like personal protective equipment. If we have somebody smoking on campus, we start with a soft approach that it's not accepted here and then ratchet it up to the normal progressive discipline process.

\section{Shared Governance vs. Timely Response}

All leaders described their decision-making processes as shared governance. Internally, faculty, staff, and students voice their thoughts and opinions through working groups, committees, and open meetings, which inform leaders' decisions, as discussed in the previous section on deliberative dialog. Several leaders observed that shared governance can impede a timely crisis response. As Emerson observed:

Shared governance is an obstacle to responding to an emergency. The faculty have been given complete autonomy over the modality they teach...They're still changing their modalities. So, it's causing the ripple effect on preparing the university and the operations and the emergency operations center, it's been rough. It's a moving target.
To navigate this tension, a few participants recommended being strategic about rethinking the structure of shared governance in a crisis. For example, Hunter recommended:

We've been making it up as we go along and changing course as we needed to. But, for me, having more clarity about this is how our structure works and this is the expectation of how decisions will be made during a crisis would have been really helpful.

\section{Discussion and Conclusion}

Crises are moments of high uncertainty and threat where stakeholders can lose trust in organizational leadership (Dirks \& Ferrin, 2002). To mitigate crisis damage, leaders must listen to their stakeholders, who may have competing crisis narratives. Leaders also must consider the power and interests underpinning their crisis claims (Spector, 2019). Prior research has advocated for putting ethics at the heart of crisis management (e.g., Thomas \& Young, 2011; Sellnow \& Seeger, 2020; St. John III \& Pearson, 2016). Yet, it is unclear how exactly leaders should integrate values into their crisis planning and responses.

Our research reveals that the COVID-19 pandemic has been a pivotal moment in which higher education leaders have turned to following a track of value rather than complicated crisis plans or detailed codes of ethics. While some leaders noted that their crisis plans were useful in the early phases of their COVID-19 responses, the long duration of the event necessitated creating responses on the fly. To navigate this highly prolonged and uncertain crisis, leaders advocated for staying true to their missions by following a track of value. We further discuss these findings below.

\section{Missions and Values (RQ1a and RQ1b)}

Our first research question asked what are the roles of (a) missions and (b) values as reflected in U.S. higher education institutions' responses to the COVID-19 pandemic? We found that leaders aligned their decision-making with their institutions' missions and values, and closely tied their institutions' identities to their missions and values. Our findings further suggest that institutions should consider adding explicit value statements to their future crisis plans. Our findings also indicate that establishing ethics committees could be instrumental in helping institutions navigate future crises. We further discuss these findings below.

First, institutions' identities come from their status as a public or private institution, religious affiliations, student body size, the populations they serve, and/or whether they have a primary research mission. Past research theorized that higher education leaders must align their leadership 
style with their institutions' cultural norms to mount a successful crisis response (Latta, 2020). Our results support this notion, demonstrating how leaders aligned their decision-making with their institutions' missions and values. For example, institutions with a religious mission heavily focused on the value of improving the lives of their community members during the pandemic. Institutions with small student bodies emphasized an ethic of care to maintain their closely knit communities. Our research further shows that when responding to the pandemic, the value of safety rose to the forefront of leaders' missions regardless of their institution type, along with the primary mission of education. Prior research theorized that organizational values are dynamic (Bourne \& Jenkins, 2013), and our paper shows how leaders balanced dynamic values during an extremely prolonged crisis.

Second, our findings suggest that higher education leaders should infuse their future crisis plans with explicit value statements derived from their missions. Previous research suggested that organizational values can guide strategic crisis responses (Altıok, 2011), especially when values are co-developed with key stakeholders (Kopaneva, 2019; Latta, 2020). Considering this prior research and our paper's findings, we conclude that the COVID19 pandemic should prompt higher education institutions to adapt their crisis plans. Specifically, they should add short statements on how their missions and values should guide future crisis responses. These statements should be co-developed with stakeholders. For example, statements could note the importance of prioritizing safety and education, protecting vulnerable community members, or safely bringing back research operations while protecting vulnerable staff members.

Third, our findings suggest that there is a benefit of forming stakeholder groups to help organizations stay true to their missions and visions when responding to crises. Only a few institutions in our sample stood up formal ethics committees, which included faculty, staff, and student representatives, to help guide their COVID-19 responses. These committees were instrumental in managing tensions such as when to return to in-person teaching, how to enforce safety guidance, and how to balance safety with financial solvency. We further propose that ethics committees could be instrumental in upholding the values of fairness and equity while serving all members of a campus community (American Association of University Administrators, 2017). In our research, institutions without missions to serve marginalized groups were less likely to focus their COVID-19 responses on serving these community members, despite the well-recognized health and social inequities of these groups (CDC, 2020b).

\section{Planning, Codes of Ethics, and Guiding Principles (RQ2 \& RQ3)}

The second and third research questions inquired about U.S. higher education institutions' guiding principles and codes of ethics for responding to the COVID-19 pandemic. Institutions in our sample were not prepared for the pandemic. Indeed, none of the leaders reported that they relied primarily on their institutions' crisis plans to respond to the pandemic, despite that the majority reported having plans that addressed infectious disease outbreaks. The pandemic eclipsed any college or university plan, requiring improvised responses. In cases such as this, values and mission statements can provide the kind of general decisional frame and direction necessary to guide responses. In this way, values both form and inform crisis responses.

Although none of the leaders reported following established codes of ethics from professional associations, many leaders advocated for following a track of value through developing and applying the following general guiding principles: (1) engage in accuracy, transparency, and accountability; (2) foster deliberative dialog; (3) prioritize safety; (4) support justice, fairness, and equity; and (5) engage in an ethic of care. Moreover, prior research has called for a "responsibility compass" to guide leaders' ethical decisionmaking (Coldwell et al., 2012, p. 142). In higher education, this responsibility compass centers on the values identified and articulated by leaders, as further discussed below.

\section{Accuracy, transparency, and accountability}

Prior research on virtuous leaders emphasized the importance of committing to the highest level of integrity (Braum et al., 2009; Sellnow \& Seeger, 2020). Leaders pointed out the importance of accurate and transparent responses to COVID-19, while also noting that communicating the science behind the pandemic is challenging. A few institutions established scientific advisory committees to provide crisis-specific expertise, which helped leaders interpret the complicated and changing science about disease transmission, vaccine efficacy, and appropriate safety measures. Having crisis-specific knowledge also enabled leaders to enact the principle of significant choice, which is the ability to communicate as completely and accurately as possible so that community members have the information they need to make important decisions (Sellnow \& Seeger, 2020; Streifel et al., 2006). When leaders do not have crisis-specific knowledge on their own or from their crisis team members, they need to obtain that knowledge from others, which can delay responses.

Additionally, our paper adds to the literature that accuracy, transparency, and accountability are closely tied to actively educating campus communities about the science 
behind crises. As leaders discussed, simply releasing COVID-19 positivity test data without educating the campus community about how to interpret the data can cause more harm than good. Prior research has extensively discussed the uncertainty inherent in crises as an ethical tension for leaders to navigate (e.g., Sellnow \& Seeger, 2020; St. John III \& Pearson, 2016). We connect effective science communication with the capacity to enact the ethical imperatives of accuracy, transparency, and accountability. Furthermore, our research adds that transparency is enhanced when leaders have crisis-specific expertise, which was health and medical expertise for the COVID-19 pandemic.

Accuracy, transparency, and accountability also related to leaders, at times, making "best guesses" or "best estimates." There was a tension between some leaders advocating for a swift " $80 \%$ solution," whereas other leaders recommended waiting to make a decision until they had more information or a change was necessary. Though this paper does not resolve this tension, leaders agreed that in order to maintain their credibility during the changing information landscape, they must have the courage and humility to admit mistakes. The literature on trust (Liu \& Mehta, 2020) suggests that if campus community members do not trust their leaders, they are unlikely to follow their institutions' COVID-19 safety policies and guidance. Our research suggests that maintaining an ethic of care may begin with leaders who readily embrace admitting their crisis response mistakes and pivot their institutions' responses to benefit their stakeholders' needs.

\section{Foster Deliberative Dialog}

Engaging in deliberative dialog helps leaders better understand stakeholders' expectations and navigate ethical tensions (Braum et al., 2009; Boin \& Nieuwenburg, 2013; St. John III \& Pearson, 2016). When crises are approached from a contextual constructivist approach, deliberative dialog helps understand stakeholders' multiple interpretations of crisis claims made by leaders (Spector, 2019). Our research supports the critical importance of deliberative dialog in higher education's response to COVID-19. Participants characterized dialog as instrumental to their crisis decision-making, especially in identifying new issues and clarifying guidance. At times, dialog resulted in changes to institutions' responses, such as how COVID-19 testing was deployed and whether faculty were required to teach in-person classes. Central to the success of dialog was building strong relationships with campus stakeholders before crises.

Across the board, leaders in our research revealed that virtual dialog is effective in meeting the same goals identified in the literature for in-person dialog. Our paper also adds to the literature that dialog does not always need to be practiced synchronously to be successful, although "live" virtual town halls remained the preferred method of deliberative dialog for our participants. Importantly, leaders shared how asynchronous dialog platforms, such as surveys and anonymous forms, clarified stakeholders' concerns and needs. Asynchronous platforms further allowed for community members to feel more comfortable providing feedback, especially given academic hierarchies and power dynamics. Furthermore, dialog can still be deliberative even if not fully planned. A few leaders advocated for spontaneous dialog such as by walking around campus and informally interacting with faculty, staff, and students.

\section{Prioritize Safety}

All of the participants discussed prioritizing their stakeholders' safety over other issues during the pandemic, as reflected in professional codes of ethics (American Public Health Association, 2019). Importantly, decisions and actions need to actually improve safety and not be just for show. In addition, response frameworks should provide guidance on how to balance safety with fiscal responsibility. Drills, exercises, and simulations should allow leaders to practice making decisions when safety guidance is conflicting or is not tailored to higher education institutions' needs. Ethics committees can help navigate these tensions, and should be included in drills, exercises, and simulations.

\section{Engage in an Ethic of Care}

As noted above, participants unanimously agreed that their highest ethical responsibility was to protect the health and safety of their community members, reflecting a strong ethic of care (St. John III \& Pearson, 2016). Participants further followed an ethic of care by fostering a supportive climate. To help support stakeholders, leaders discussed a variety of initiatives including social media videos and interactive campaigns, creative virtual events, handwritten cards from senior leadership, and small thank-you gifts. Some leaders discussed institutionalizing an ethic of care through new initiatives. For example, one leader discussed a new program for faculty and staff to volunteer to support students' wellbeing through regular text messages. Other leaders discussed creating new training programs to help faculty succeed in the virtual teaching environment. All of these initiatives were created on the fly, and can serve as fodder for modifying crisis plans.

\section{Support Justice, Fairness, and Equity}

Almost half of our participants emphasized the importance of considering justice, fairness, and equity in their COVID19 responses, in line with prior research on the importance 
of social responsibility and justice (Braum et al., 2009; Leider et al., 2017; Sellnow \& Seeger, 2020). As previously discussed, institutions with missions that focused on marginalized communities were more likely to invoke justice in their COVID-19 responses. To support justice, leaders discussed extending existing services (e.g., laptop loans, campus pantries) rather than creating new services. Only one participant discussed creating a working group on inclusion and equity to examine how COVID-19 has disproportionately impacted community members of color. Many participants, however, discussed considering how the pandemic has impacted these communities on their campuses.

Most commonly, leaders discussed actions and policy changes that reflected fairness and equity for all such as shifting to pass/fail grading systems, having campus community members sign safety pledges, requiring campus members to watch safety videos, and launching social media compliance campaigns. We conclude that when responding to future crises leaders should consider actions and policy changes that specifically help marginalized groups to balance the need for equity and fairness with help for those most affected by the pandemic (i.e., justice). Crises may open up spaces to upend norms (Spector, 2019), but only if leaders are open to questioning the status quo.

\section{Ethical Tensions (RQ4)}

The last research question investigated how U.S. higher education institutions responded to ethical tensions during the COVID-19 pandemic. Prior research found that common ethical dilemmas during pandemics are decisions about prioritizing access to scarce supplies, considering health inequities while enacting restrictions, and fulfilling responsibilities to protect all stakeholders (Thomas \& Dasguputa, 2020; Wynia, 2007). Our participants identified additional tensions not found in the literature: mission vs. financial solvency, competing stakeholders' desires, compliance challenges, and shared governance vs. a timely response.

To balance these tensions, higher education institutions engaged in deliberative dialog. At times, leaders had to make difficult decisions, and they often relied on their institutions' missions and values to do so. As we previously noted, infusing future crisis plans with explicit values statements, standing up ethics committees, developing crisis teams with crisis-specific knowledge, and focusing responses on diversity and inclusion can help leaders navigate these tensions. Furthermore, crisis exercises, drills, and simulations should model the tensions identified in this paper so that crisis teams are better able to manage these tensions and new ones that emerge during future crises.

\section{Limitations}

The results of this research are limited by several factors. First, the findings only apply to U.S. higher education institutions, though we know COVID-19 has swept the globe. In other words, this study is just one interpretation of how higher education leaders responded to the pandemic.

Second, while we sought a diverse sample, the leaders who volunteered to participate may not be representative of the leaders who declined to participate. For example, those who declined to participate may be less focused on infusing values into their crisis responses. As Spector (2019) advocated, understanding other narratives can help "appraise claims" in a manner that is thoughtful and critical (p. 221). Accordingly, future research is needed on how other organizations responded to the pandemic. Critically, research is needed on how stakeholders assess U.S. higher education institutions' COVID-19 responses, as well as stakeholder assessments of other organizations' responses.

Third, the findings reflect how leaders navigated the early stages of the pandemic, but not the entire crisis. The benefit of conducting research during the pandemic is that we gained insights that are not hindered by retrospective bias (Fischhoff et al., 2005). While gaining these insights has been instrumental, the story of COVID-19 is still being told. As noted above, there are no doubt other narratives about the pandemic.

Lastly, our sample included a variety of higher education institution types, but more than half of our participants lead four-year public universities. This sampling limitation may make our findings less transferrable to a variety of U.S. higher education types.

\section{Conclusion}

When we wrote this paper, 29.3 million people in the United States had contracted COVID-19 resulting in 532,355 deaths (CDC, 2021). Per capita deaths in the United States, both from COVID-19 and other causes, were 18 times higher than in other high-income countries (Bilinski \& Emanuel, 2020). Against this startling backdrop, higher education leaders have navigated ethical tensions and made difficult decisions.

Our research reveals that higher education institutions' missions and values should explicitly inform their crisis planning. We offer that creating shared values, tied to missions, before crises can serve as a moral compass to help leaders navigate tensions and tough decisions during crises. This moral compass should come from shared norms while considering each institution's unique mission. This paper reveals the following somewhat universal guiding principles that can inform crisis planning in higher education settings: (1) engage in accuracy, transparency, and accountability; (2) 
foster deliberative dialog; (3) prioritize safety; (4) support justice, fairness, and equity; and (5) engage in an ethic of care. However, leaders did not explicitly include these guiding principles in their crisis plans. Instead, they emerged organically in their responses. Our research calls for explicit integration of shared values into future plans and planning activities. Our research also calls for standing up ethics committees composed of diverse stakeholders to help higher education institutions navigate the tensions inherent in crises. Furthermore, when leaders do not have adequate public health or medical expertise, it is imperative that their crisis management teams include such experts. In addition to involving experts, it is critical for leaders to engage in deliberative dialog with their stakeholders with the goal of listening rather than obtaining endorsement of leaders' plans.

As we conclude this paper, the COVID-19 pandemic has lasted more than a year, and experts note that the end of the pandemic is hard to predict (McKinsey, 2021). Perhaps even more alarming is that experts are already forecasting the next pandemic (Spinney, 2021). Given the dearth of prior research on the intersection of ethics, values, principles, and crisis management, we hope that this paper serves as a call to action for additional research, especially with stakeholders. There is more unknown than known about how organizations can partner with stakeholders to protect their communities during crises. If college and universities infuse shared values into their future planning activities, they will not have to develop a moral compass on the fly for the next pandemic. Higher education leaders also will be confident that their crisis responses are grounded in their communities' shared values.

Funding This study was funded by the University of Maryland's coronavirus seed grant program.

\section{Declarations}

Ethical Approval This study was approved by the University of Maryland Institutional Review Board (ethics approval \#1583498-4) and the Wayne State University Institutional Review Board (ethics approval \#1583498). The University of Central Florida Institutional Review Board also administratively approved the study, but did not provide a separate approval number. At the time this research was conducted, co-author America L. Edwards was a master's student at the University of Central Florida. All leaders provided written consent to participate in the study.

\section{References}

Altıo, P. (2011). Applicable vision, mission and the effects of strategic management on crisis resolve. Procedia-Social and Behavioral Sciences, 24, 61-71. https://doi.org/10.1016/j.sbspro.2011.09.057
American Association of University Administrators (2017). Ethical principles for college and university administrators. http://www. aaua.org/pdf/Ethical-Principles.pdf

Auger, G. A. (2014). Trust me, trust me not: An experimental analysis of the effect of transparency on organizations. Journal of Public Relations Research, 26(4), 325-343. https://doi.org/10.1080/1062726X. 2014.908722

Bilinski, A., Emanuel, E. J. (2020). COVID-19 and excess all-cause mortality in the US and 18 comparison countries. Journal of the American Medical Association. Advance online publication. https://doi. org/https://doi.org/10.1001/jama.2020.20717

Boin, A., \& Nieuwenburg, P. (2013). The moral costs of discretionary decision-making in crisis: Hurricane Katrina and the memorial hospital tragedy. Public Integrity, 15(4), 367-384. https://doi.org/10.2753/ PIN1099-9922150403

Bourne, H., \& Jenkins, M. (2013). Organizational values: A dynamic perspective. Organizational Studies, 34(4), 495-514. https://doi.org/10. 1177/2F0170840612467155

Braum, N. M., Jacobson, P. D., \& Goold, S. D. (2009). "Listen to the people": Public deliberation about social distancing measures in a pandemic. The American Journal of Bioethics, 9(11), 4-14. https://doi. org/10.1080/15265160903197531

Campbell, A., \& Yeung, S. (1991). Creating a sense of mission. Long Range Planning, 24(4), 10-20. https://doi.org/10.1016/0024-6301(91) 90002-6

CDC, Centers for Disease Control and Prevention (2020a). Interim guidance for administrators of US institutions of higher education. https:// www.cdc.gov/coronavirus/2019-ncov/community/guidance-ihe-respo nse.html

CDC, Centers for Disease Control and Prevention (2020b). Health equity considerations and racial and ethnic minority groups. https://www. cdc.gov/coronavirus/2019-ncov/community/health-equity/race-ethni city.html

CDC, Centers for Disease Control and Prevention (2021). COVID data tracker. https://covid.cdc.gov/covid-data-tracker/\#datatracker-home

Cochran, D. S., \& David, F. R. (1986). Communication effectiveness of organizational mission statements. Journal of Applied Communication Research, 14(2), 108-118. https://doi.org/10.1080/0090988860 9360308

Coldwell, D. A. L., Joosub, T., \& PaPagergiou, E. (2012). Responsible leadership in organizational crises: An analysis of the effects of public perceptions of selected SA business organization' reputation. Journal of Business Ethics, 109(2), 133-144. https://doi.org/10.1007/ s10551-011-1110-8

Coombs, W. T. (2019). Ongoing crisis communication: Planning, managing, and responding. (5th ed.). Sage.

Corbin, J., \& Strauss, A. (2015). Basics of qualitative research: Techniques to developing grounded theory. (4th ed.). Sage.

Dirks, K. T., \& Ferrin, D. I. (2002). Trust in leadership: Meta-analytic findings and implications for organizational research. Journal of Applied Psychology, 87(4), 611-628. https://doi.org/10.1037/0021-9010.87.4. 611

Erwin, P. (2011). The effects of code content and quality on ethical performance. Journal of Business Ethics, 99(4), 545-548.

Fischhoff, B., Gonzalez, R. M., Lerner, J. S., \& Small, D. A. (2005). Evolving judgements of terror risks: Foresight, hindsight, and emotion. Journal of Experimental Psychology Applied, 11(2), 124-139. https:// doi.org/10.1037/1076-898x.11.2.124

Gigliotti, R. A. (2016). Leader as performer; leader as human: A discursive and retrospective construction of crisis leadership. Atlantic Journal of Communication, 24(4), 185-200. https://doi.org/10.1080/15456870. 2016.1208660

Ha, J. H., \& Riffe, D. (2015). Crisis-related research in communication and business journals: An interdisciplinary review from 1992-2011. Public Relations Review, 41(4), 569-578. https://doi.org/10.1016/j. pubrev.2015.06.019 
Heath, R. L. (2006). Onward into more fog: Thoughts on public relations' research directions. Journal of Public Relations Research, 18(2), 93-114. https://doi.org/10.1207/s1532754xjprr1802_2

Hess, A. (2020). How coronavirus dramatically changed college for over 14 million students. CNBC. https://www.cnbc.com/2020/03/ 26/how-coronavirus-changed-College-for-over-14-million-stude nts.html

Hodge, J. G., Hanfling, D., \& Powell, T. P. (2013). Practical, ethical, and legal challenges underlying crisis standards of care. Journal of Law, Medicine, and Ethics, 42(Suppl 1), 50-55. https://doi.org/ 10.1111/jlme.12039

Huang, Y.-H. (2004). Is symmetrical communication ethical and effective? Journal of Business Ethics, 53(4), 333-352. https://doi.org/ 10.1023/B:BUSI.0000043494.17425.c6

Kopaneva, I. M. (2019). Left in the dust: Employee constructions of mission and vision ownership. International Journal of Business Communication, 56(1), 122-145. https://doi.org/10.1177/2F232 9488415604457

Latta, G. F. (2020). Modelling the interaction of leadership, culture and power in higher education. Journal of Further and Higher Education, 44(9), 1188-1206. https://doi.org/10.1080/0309877X. 2019.1669770

Leider, J. P., DeBruin, D., Reynolds, N., Koch, A., \& Seaberg, J. (2017). Ethical guidance for disaster response, specifically around crisis standards of care: A systematic review. American Journal of Public Health, 107(9), e1-29. https://doi.org/10.2105/AJPH.2017.303882

Lindlof, T. R., \& Taylor, B. C. (2011). Qualitative communication research methods. (3rd ed.). Sage.

Littlefield, R. S., Reierson, J., Cowden, K., Stowman, S., \& Feather, C. L. (2009). A case study of the Red Lake, Minnesota, school shooting: Intercultural learning in the renewal process. Communication, Culture \& Critique, 2(3), 361-383. https://doi.org/10.1111/j.17539137.2009.01043.x

Liu, B. F., Jin, Y., Briones, R., \& Kuch, B. (2012). Managing turbulence in the blogosphere: Evaluating the blog-mediated crisis communication model with the American Red Cross. Journal of Public Relations Research, 24(4), 353-370. https://doi.org/10.1080/10627 26X.2012.689901

Liu, B. F., \& Mehta, A. (2020). From the periphery and towards a centralized model for trust in government risk and disaster communication. Journal of Risk Research. Advance online publication. https://doi.org/https://doi.org/10.1080/13669877.2020.1773516

Louden, R. B. (1992). Morality and moral theory. Oxford University Press.

Maak, T., \& Pless, N. (2006). Responsible leadership. Routledge.

McKinsey. (2021). When will the COVID-19 pandemic end? https:// www.mckinsey.com/industries/healthcare-systems-and-services/ our-insights/when-will-the-covid-19-pandemic-end\#

Moerschell, L., \& Novak, S. S. (2020). Managing crisis in a university setting: The challenge of alignment. Journal of Contingencies and Crisis Management, 28(1), 30-40. https://doi.org/10.1111/14685973.12266

Pearson, C. M., Clair, J. A., Misra, S. K., \& Mitroff, I. I. (1997). Managing the unthinkable. Organizational Dynamics, 26(2), 51-64. https://doi.org/10.1016/S0090-2616(97)90005-X

Phillips S., Knebel A., \& Johnson K. (2009). Mass medical care with scarce resources: The essentials. Agency for Healthcare Research and Quality. https://www.hsdl.org/?view\&did=28175

Pullen, A., \& Vachhani, S. J. (2020). Feminist ethics and women leaders: From difference to intercorporeality. Advance online publication. Journal of Business Ethics. https://doi.org/https://doi.org/10. 1007/s10551-020-04526-0

Prewitt, J. E., \& Weil, R. (2014). Organizational opportunities endemic in crisis leadership. Journal of Management Policy and Practice, 15(2), 72. http://m.www.na-businesspress.com/JMPP/PrewittJE_ Web15_2_.pdf
Rawlins, B. (2009). Give the emperor a mirror: Toward developing a stakeholder measurement of organizational transparency. Journal of Public Relations Research, 21(1), 71-99. https://doi.org/10. 1080/10627260802153421

Sellnow, T., \& Seeger, M. (2020). Theorizing crisis communication (2nd Ed.). Wiley.

Seeger, M. W., \& Ulmer, R. R. (2001). Virtuous responses to organizational crisis: Aaron Feuerstein and Milt Cole. Journal of Business Ethics, 31(4), 369-376. https://www.jstor.org/stable/25074543

Spector, B. (2019). Constructing crisis: Leaders, crises, and claims of urgency. Cambridge University Press.

Spinney, L. (2021). The next pandemic? It may already be upon us? The Guardian. https://www.theguardian.com/commentisfree/2021/feb/ 15/creating-conditions-next-pandemic-antibiotics

Stevens, B. (1994). An analysis of corporate ethical code studies: Where do we go from here? Journal of Business Ethics, 13(1), 63-69. https://doi.org/10.1007/BF00877156

Stevens, B., \& Buechler, S. (2013). An analysis of Lehman Brothers code of ethics and the role it played in the firm. Journal of Leadership, Accountability, and Ethics, 10(1), 43-57

Streifel, R. A., Beebe, B. K., Veil, S., \& Sellnow, T. L. (2006). Significant choice and crisis decision making: MeritCare's public communication in the fen-phen case. Journal of Business Ethics, 69(4), 389-397. https://doi.org/10.1007/s10551-006-9097-2

St. John, B., III., \& Pearson, Y. E. (2016). Crisis management ethics: Moving beyond the public-relations-person-as-corporate-conscience construct. Journal of Media Ethics, 31(1), 18-34. https:// doi.org/10.1080/23736992.2015.1116392

The American Public Health Association (2019). Public health code of ethics. https://www.apha.org/-/media/files/pdf/membergroups/ ethics/code_of_ethics.ashx

The Carnegie Classification of Institutions of Higher Education. (2020). About Carnegie Classification. http://carnegieclassifications.iu. edu/.

The Chronicle of Higher Education. (2020). Coronavirus hits campus: Special edition. https://www.chronicle.com/specialreport/Coron avirus-Hits-Campus/275

Thomas, J. C., \& Dasgupta, N. (2020). Ethical pandemic control through the public health code of ethics. American Journal of Public Health, 110(8), 1171-1172. https://doi.org/10.2105/AJPH. 2020.305785

Thomas, J. C., Dasgupta, N., \& Martinot, A. (2007). Ethics in a pandemic: A survey of the state pandemic influenza plans. American Journal of Public Health, 97(supp 1), S26-S31. https://doi.org/10. 2105/AJPH.2006.093443

Thomas, J. C., \& Young, S. (2011). Wake me up when there's a crisis: Progress on state pandemic influenza ethics preparedness. American Journal of Public Health, 101(11), 2080-2082. https://doi.org/ 10.2105/AJPH.2011.300293

Ulmer, R. R., \& Sellnow, T. L. (2000). Consistent questions of ambiguity in organizational crisis communication: Jack in the Box as a case study. Journal of Business Ethics, 25(2), 143-155. https://doi. org/10.1023/A:1006183805499

Varma, T. M. (2020). Responsible leadership and reputation management during crisis: The cases of Delta and United Airlines. Journal of Business Ethics. Advance online publication. https://doi. org/https://doi.org/10.1007/s10551-020-04554-w

Wynia, M. K. (2007). Ethics and public health emergencies: Encouraging responsibility. The American Journal of Bioethics, 7(4), 1-4. https://doi.org/10.1080/15265160701307613

Publisher's Note Springer Nature remains neutral with regard to jurisdictional claims in published maps and institutional affiliations. 